\title{
PETROGLIFOS DO ABRIGO DO BARREIRO
}

\author{
Taís Vargas Lima* \\ José Proenza Brochado**
}

\section{INTRODUÇÃO}

O município de Ivorá está localizado aproximadamente aos $29^{\circ} 30^{\prime}$ de latitude Norte e aos $54^{\circ} 25^{\prime}$ de longitude Oeste, à cerca de 200 metros acima do nível do mar. Fica na divisa de duas grandes províncias geomorfológicas do Rio Grande do Sul: o planalto Sul-Riograndense e a Depressão Central Periférica. O relevo se apresenta dissecado, configurando colinas de topo convexo e encostas íngremes, com a ocorrência de linhas de pedra, tal como encontramos no Abrigo do Barreiro, a cerca de $9 \mathrm{~km}$ da sede do município.

O abrigo do Barreiro e outros 15 sítios arqueológicos apresentam petroglifos nas paredes ou no teto (Schmitz e Brochado 1982: Fig. 1), e estes estão localizados nos alinhamentos de arenitos no sopé da escarpa da Serra Geral. Conhecido como Formação Botucatu (série São Bento), estes arenitos são avermelhados, porosos e permeáveis. Foram originados por deposiçāo eólica em antigo ambiente desértico, de aridez rigorosa. Sofreram processos erosivo mesmo antes dos sucessivos derrames basálticos fissurais que os cobriram (Formação Serra Geral).

- Graduada no Curso de Ciências Sociais (IFCH/PUCS) e bolsista da FAPERGS.

* *Professor do Curso de Pós-Graduação em História (IFCH/PUCS) 
Estes arenitos apresentam estratificação cruzadas, planos de truncamento definidos, diácclases (ou fraturas) e solapamento basal ou seja, o ataque erosivo - físico-químico - ocorre a partir das fissuras desde a base.

O ambiente atual apresenta como principais características a ocorrência de clima subtropical úmido, sem estação seca e com verões quentes. Segundo a classificação de Koeppen temos "Cfa", onde há ocorrência de pelo menos $30 \mathrm{~mm}$ de chuvas mensais e, pelo menos, um mês, a cada ano, com temperatura média superior à $22^{\circ} \mathrm{C}$. $\mathrm{O}$ mês mais quente é o de janeiro, com temperatura média de $23,2^{\circ} \mathrm{C}$. $\mathrm{O}$ mês mais frio é o de julho, com temperatura média de $12,8^{\circ} \mathrm{C}$. A temperatura média anual é de $17,1^{\circ} \mathrm{C}$. A precipitação média é de 1.750 a $1.900 \mathrm{~mm} / \mathrm{ano}$. Os meses mais chuvosos são maio, junho e setembro e os meses menos chuvosos, novembro, dezembro e fevereiro. Ocorrem de 110 a 130 dias de chuvas, bem distribuídas, a cada ano.

A insolação aproximada em Ivorá é de 2.100 a 2.200 horas anuais e as maiores incidências ocorrem nos meses de dezembro e janeiro. Os nevoeiros são freqüentes em grande parte do ano, ocorrendo principalmente entre os meses de abril a agosto. Ocorrem, em média, 16 a 21 geadas por ano, mais freqüentes de março a novembro. A umidade relativa do ar é de 75 a $85 \%$.

O solo da região é fortemente ácido, com ph em torno de 5,0, de coloração bruno avermelhada escura, apresenta textura argilosa é medianamente profundo (menos de $130 \mathrm{~cm}$ ). É classificado "como solo laterítico bruno avermelhado distrófico" (Levantamento de Reconhecimento dos Solos do Estado do RS, 1973) unidade de mapeamento Oásis.

A região apresenta vegetação classificada como "floresta subcaducifólia subtropical” (Geografia do Brasil, 1977). Os cultivos são variados, anuais e perenes. Além da policultura, há também a pecuária. As propriedades possuem pequenas dimensões e são ocupadas pelos descendentes de imigrantes europeus, que produzem basicamente para consumo próprio (auto-sustento).

Os dados geológicos, geomorfológicos e ambientais foram organizados por Gislene Monticelli a partir de Ab'Saber (1977), Aspectos... (1972), Geografia do Brasil (1963, 1977, 1990), Guerra (1972), Levantamento... (1973) e Moreno (1961). 
Os 16 sítios referidos foram o único conjunto de abrigos com petroglifos do Rio Grande do Sul, se exceptuarmos notícias de um local no município de Livramento (Maria Elena Schorr com. pes.)

Diferentes sítios foram localizados, cadastrados e pesquisados pelo P. Daniel Cargnin, P. José Pivetta, José Proenza Brochado, Pedro Ignácio Schmitz, Pedro Augusto Mentz Ribeiro e Eurico Th. Miller. A bibliografia inclui: Brochado 1969: 50-54; 1971: 14-15, 25-26; Brochado e Schmitz 1976; 1982; Ribeiro 1969-1970; 1972; 1974; 1978; Ribeiro, Baumhardt, Martin, Heuser e Steinhaus 1973; Schmitz e Brochado 1972; 1972-1973.

O abrigo do Barreiro assim como o abrigo Mouro, o da Linha São José e mais um sítio com blocos grandes separados, foram os últimos a serem localizados, tendo sido descobertos entre 1970 a 1990, pelo P. Daniel Cargnin, nos municípios de Ivorá e Mata respectivamente a nordeste e a noroeste de Santa Maria (Fig. 11: 1, 2, 3, e 8) (Belinasso 1984).

Em dezembro de 1992 Taís Vargas Lima e Claudio Batista Carle efetuaram um trabalho de campo preliminar para levantamento dos sítios arqueológicos na região de Ivorá e cadastramento do abrigo do Barreiro RS 452-1.

Tendo sido concedida a verba solicitada à Fundação de Amparo à Pesquisa no Rio Grande do Sul (FAPERGS) para efetuar a escavação do abrigo e o relevantamento dos petroglifos e obtida a licença do IBPC no processo $\mathrm{n}^{2} 01450.000582-91$ segundo a portaria $\mathrm{n}^{2} 308$, um grupo de 15 pessoas, entre professores, mestrandos e graduandos de arqueologia, permaneceram durante 20 dias no local, entre 02 e 24 de julho de 1993 . A escavação foi dirigida por Klaus P. C. Hilbert e a cópia dos petroglifos por J. Proenza Brochado. O material escavado e as cópias dos petroglifos foram levados para o Centro de Estudos e Pesquisas Arqueológicas (CEPA) do Instituto de Filosofia e Ciências Humanas (IFCH) da Pontifícia Universidade Católica do Rio Grande do Sul (PUCRS), onde estão sendo executados os trabalhos. 


\section{DESCRIÇÃO DO RS - 452-1: ABRIGO DO BARREIRO}

O abrigo do Barreiro está situado a $7 \mathrm{~km}$, por estrada, da sede do município de Ivorá, se abre num paredão voltado para o norte $70 \mathrm{~m}$ acima do fundo do vale e aproximadamente $200 \mathrm{~m}$ s.n.m.

No paredão quase vertical existe uma concavidade de apenas $3 \mathrm{~m}$ de profundidade e $8 \mathrm{~m}$ de largura, com uma altura máxima de $5 \mathrm{~m}$. A concavidade esta orientada para o Norte e a área abrigada por ela e disponível para a ocupação humana não ultrapassa os $24 \mathrm{~m}^{2}$.

As esfoliações são causadas por quedas de blocos de teto, se concentram nos dois extremos do abrigo e na linha de goteira do teto. $\mathrm{Na}$ parede do fundo, aproximadamente plana e bastante inclinada para fora estão concentrados todos os petroglifos, formando um conjunto de $7 \mathrm{~m}$ de comprimento $2.5 \mathrm{~m}$ de altura, cuja a área total é de $17,5 \mathrm{~m}^{2}$ (Fig. 2)

$\mathrm{Na}$ base do paredão, $70 \mathrm{~m}$ na direção $\mathrm{NO}$ se encontra um bloco medindo $70 \mathrm{~cm}$ de altura por $39 \mathrm{~cm}$ de largura e $30 \mathrm{~cm}$ de espessura, provavelmente rolado de um outro abrigo situado mais a oeste no mesmo paredão e atualmente desmoronado. Neste bloco se observam também alguns petroglífos. (Fig. 2: extremo esquerdo inferior, separado por tracejado).

A vegetação que encobre o paredão é de floresta mista e a água mais próxima se encontra em três nascentes a $6 \mathrm{~m}$ do abrigo.

A maior parte do painel principal se compõe de uma grande quantidade de perfurações de dimensões variadas e sulcos predominantemente retilíneos, diversamente orientados, que podem estar separados ou combinados entre si. Sulcos e perfuraçōes foram executados pela técnica do polimento.

Existe também uma grande quantidade de perfurações de origem natural resultantes da erosão alveolar no arenito da parede e as vezes é difícil distingui-las das perfurações artificiais. Além disso muitas das perfurações aparentemente naturais foram aprofundadas ou receberam acréscimo de sulcos.

É muito comum a sobreposição de motivos distintos, principalmente a de perfurações menores no interior de outra perfuraçōes maiores ou de sulcos ou então a de perfurações maiores no interior das "grades" formadas pelos sulcos entrecruzados. Apesar destas sobreposições não 
foi possível estabelecer uma diacronia, como no caso dos abrigos anteriormente estudados no Rio Grande do Sul, situados mais para leste.

Os petroglifos foram copiados pela sobreposição com folha de plástico transparente, usando canetas de várias cores próprias para retroprojetar. A largura e a profundidade dos sulcos e perfuraçōes foram medidas e anotadas junto aos desenhos destes.

Em laboratório os motivos foram redesenhados em escala reduzida a 1:5 (Fig. 2). Este trabalho, assim como a classificação dos motivos foi realizado por Taís Vargas Lima.

$\mathrm{Na}$ cópia dos petroglifos foram usados as seguintes convenções:

- Traços cheios ou áreas. cobertas de preto indicam sulcos ou perfurações entre 0.1 e $4,5 \mathrm{~cm}$.

- Áreas ponteadas indicam perfurações com profundidades de 4,5 $\mathrm{cm}$ até $15 \mathrm{~cm}$.

- Áreas delimitadas por traços cheios indicam depressões rasas.

- Áreas delimitadas por tracejado, brancas ou preenchidas de ponteados, indicam depressōes cujas margens não são bem claras.

- Linhas finas, inclinadas, de traços e pontos, indicam diáclases (fraturas naturais), as quais de certa forma serviram para orientar a disposição dos petroglifos superiores.

- A linha ondulada de pontos e traços na parte inferior do painel decorado indica uma reentrância na base da parede do abrigo que forma como que um abrigo menor, atualmente encoberto por sedimentos e blocos de arenitos despreendidos.

- Ainda mais abaixo está indicado o nível do piso atual do abrigo e a primeira fila de estacas do quadriculamento da área escavada, com seus respectivos números. As letras maiúsculas indicam a divisão em subpainéis verticais de $1 \mathrm{~m}$ de largura.

\section{TÉCNICA DE PRODUÇÃO DOS PETROGLIFOS}

Todos os petroglifos foram gravados pela técnica do polimento. A maior parte dos sulcos apresentam secção em U e medem de 3 a $20 \mathrm{~cm}$ largura, com profundidades, desde $1 \mathrm{~mm}$ até $18 \mathrm{~cm}$. Alguns sulcos 
apresentam secção em V, muito aguda. As perfurações medem desde 2 até $10 \mathrm{~cm}$ de diâmetro, com profundidade desde 2,5 até $9 \mathrm{~cm}$.

Se observam também depressões rasas e áreas rebaixadas, parcialmente polidas. Não se observam sulcos ou perfurações executados pela técnica do picoteamento.

\section{CLASSIFICAÇÃO DOS MOTIVOS DOS PETROGLIFOS}

Na classificação dos motivos dos petroglifos seguimos o sistema adotado por Schmitz e Brochado (1982: 9-10, 22-3 e 34, Fig: 9, 18) para a apresentação e comparação dos petroglifos dos abrigos RS-MJ-15: Canhemborá, RS-MJ-53 A, B e C: linha Sétima, RS-MJ-102: Lajeado dos Dourados e RS-SM-7: Pedra Grande. No abrigo do Barreiro nāo se observam os motivos: E, H. K e M, e foram classificados os motivos: U, V, W, Y e Z, que não se obervam nos anteriores (Fig. 3).

A. Sulcos retilíneos, aproximadamente verticais, isolados ou em alinhamentos paralelos.

B. Sulcos retilíneos que tendem a convergir.

C. Sulcos retilíneos que se encontram em ângulo reto ou agudo.

D1. Sulcos retilíneos convergentes para um ponto.

D2. Sulcos retilíneos que se encontram formando ângulos agudos.

D3. Sulcos retilíneos que convergem para uma perfuração.

F. Sulcos retilíneos, alguns deles paralelos, que se cortam ou se encontram formando ângulos agudos.

G. Sulcos retilíneos que se encontram ou se cortam perpendicularmente.

I. Combinações de sulcos retilíneos paralelos que se cortam perpendicularmente ou que estão delimitadas por sulcos curvilíneos.

J. Campos delimitados com sulcos curvilíneos dentro dos quais existem sulcos retilíneos paralelos, convergentes ou cruzados.

L. Sulcos curvilíneos isolados ou paralelos.

N.-O. Perfurações isoladas ou agrupadas assimetricamente.

P. Perfurações alinhadas horizontalmente em fileiras simples ou paralelas.

Q. Grandes depressões simples. 
R. Depressões com sulcos irradiantes ou secantes.

S. Uma depressão acompanhada de três ou quatro perfurações; talvez representando pegada de felino.

T. Depressões delimitadas por sulcos, curvilíneos ou não, contendo um sulco retilíneo vertical; talvez representando símbolos sexuais femininos.

U. Sulcos ondulantes simples.

V. Combinações de sulcos retilíneos ou curvilíneos.

W. Depressões combinadas com sulcos retilíneos ou curvilíneos.

Y. Formas complexas combinando sulcos curvilíneos, retilíneos convergentes e depressões.

Z. Três sulcos retilíneos convergentes; talvez representando pegada de ave. Se diferenciam dos motivos $\mathrm{C}$ e $\mathrm{D}$ por serem mais largas e profundas.

Reconhecemos agora a dificuldade de segregar os motivos, uma vez que os sulcos e perfurações se encontram todos muito próximos uns dos outros e muitas vezes superpostas. Qualquer tentativa de isolar motivos só pode ser feita arbitrariamente na maior parte dos casos. Também não sabemos como os indígenas viam os petroglifos e que relaçôes fariam entre eles.

No entanto para podermos continuar as comparações destes petroglifos com os dos abrigos anteriormente pesquisados tivemos que usar o mesmo sistema adotado então.

Como a única técnica observada nos sulcos e perfurações é a do polimento e dado o conjunto dos motivos presentes (Fig. 3 e 4) os petroglifos do abrigo do Barreiro correspondem ao estilo B, identificado anteriormente nos abrigos da Pedra Grande e da Linha Sétima (Schmitz e Brochado 1982:38).

Observando-se o gráfico da Fig. 4, no abrigo do Barreiro existe também uma alta frequêencia dos motivos $\mathrm{A}, \mathrm{B}, \mathrm{N}-\mathrm{O}$ e $\mathrm{Q}$ e uma pequena freqüência dos demais motivos, que pode ser comparado aos gráficos $3 \mathrm{e}$ 4 do artigo referido, p. 36 . 


\section{AGRADECIMENTO}

As pesquisas de campo, os trabalhos de laboratório e a redação deste artigo se tornaram possíveis devido ao auxílio e a bolsa de iniciação científica fornecido pela fundação de Amparo à Pesquisa no Rio Grande do Sul (FAPERGS) ao Centro de Estudos e Pesquisas Arqueológicas (CEPA-IFCH) da PUCRS.

Agradecemos à Prefeitura Municipal de Ivorá, ao Prefeito Onildo Sarze, e à família Paulo Moro, Marilene Moro e Daniel Moro pelas facilidades obtidas em campo. Um agradecimento especial ao Pe. Daniel Cargnin pela descoberta do abrigo do Barreiro e pelos cuidados de preservação deste sítio arqueológico.

À equipe que participou da pesquisa de campo, constituída dos seguintes: José Proenza Brochado e Klaus Peter Hilbert (orientadores) e aos alunos Taís Vargas Lima, Gilmara Mariana Cecílio, Ricardo Antônio da Silveira, Aline Saltti Escobar, Mateus Roberto Carle, Miriam Baptista Carle, Sandro Folle, João Felipe da Costa, Vera Lúcia T. Thadeu, Beatriz dos Santos Landa, Maria Madalena do Amaral, Gislene Monticelli, Junior Marques Domicks, Joaquim Jorge S. Buchaim, Sirley Elaine Hoeltz.

\section{REFERÊNCIAS BIBLIOGRÁFICAS}

AB'SABER, Aziz Nacib. Potencialidades paisagísticas brasileiras. In: Geomorfologia, 55. São Paulo, USP, 1977. 27p.

ASPECTOS Gerais do Clima do Estado Ministério da Agricultura/INCRA, 1972. v. II. BELINASSO, Diac. Severino T. Ivora 100 anos de História 1983 - Berço de Alberto Pasqualine. Santa Maria.

BROCHADO, José Proenza. Pesquisas arqueológicas nos vales do Jacuí e Ijuí. In PRONAPA, Resultados Prelim. III ano, 1967-8. Publ. Avulsas Mus. Pe. Emilio Goeldi. Belém. v. 13, p. 50-4, 1969.

- Extensão das pesquisas arqueológicas nos vales do Jacuí e Icuí Mirim, Rio Grande do Sul. In PRONAPA, Resultados Preliminares, IV ano, 1968-9. Publ. Avulsas Mus. Pe. Emilio Goeldi, Belém, v. 15, n. 14-15, p. 225-26, 1971.

- Petroglifos no Estilo de Pisadas no Rio Grande do Sul. Estudos Ibero-Americanos.

Departamento de História/PUCRS, v. II, n. 1, p. 93-145, 1976.

Geografia do Brasil. Rio de Janeiro, IBGE/CNG, 1963. Tomo I.

Geografia do Brasil. Região Sul. Rio de Janeiro, FIBGE, 1977. v. 5.

Geografia do Brasil. Rio de Janeiro, FIBGE, 1990.

GUERRA, Antonio Bezerra. Dicionário Geologico-Geomorfologico. Rio de Janeiro, IBGE, 1972. 
LEVANTAMENTO de reconhecimento dos solos do Estado do Rio Grande do Sul. Bol. Técnico, Recife, Ministério da Agricultura, 1973. n. 30.

MORENO, José. Clima do Rio Grande do Sul. Porto Alegre, Secretaria da Agricultura, 1961. 42p.

RIBEIRO, Pedro Augusto Mentz. Inscrições Rupestres no Vale do Rio Caí, RS/Brasil (Nota Prévia). In Anales de Arqueología y Etnologia. Mendonza, v. 24-5, p. 124, 1969-70.

- Petroglifos do Sítio RS-T-14: Morro do Sobrado, Montenegro, RGS/Brasil. In Iheringia, Porto Alegre, Mus. Rio Grandense Ciências Naturais, Antropologia, v. 2, p. 6, 8, 1973.

- Os petroglifos de Cerro Alegre, Santa Cruz do Sul, RS/Brasil. (Nota Prévia). Revista do CEPA, Santa Cruz do Sul, Centro de Ensino e Pesquisas Arqueológica, v. 1, 1974.

- Arte Rupestre no Sul do Brasil. Revista do CEPA, Santa Cruz do Sul, Associação Pré-ensino em Santa Cruz (APESC), n. 7, p. 1-23, 1978.

RIBEIRO, Pedro Augusto Mentz (Ed.), BAUMHARDT, Gastão Carlos, MARTIN, Hardy Elmiro, HAUSER, Lothor Frederico, STEINHAUS, Roberto. Novos petroglifos na encosta centro-oriental da Serra Geral, RS/BRASIL. (Nota prévia). In Museu Colégio Mauá - Antropologia, Santa Cruz do Sul, v. 2, p. 3-28, 1973.

SCHMITZ, Pedro Ignácio \& BROCHADO, José Proenza. Datos para una secuencia cultural del Estado de Rio Grande do Sul/Brasil, publ. 2, 1972.

. "Aleros y cuevas con petroglifos e industria lítica de la escarpa del planalto meridional, em Rio Grande do Sul/Brasil”, redigida pelos mesmos dois autores, foi publicado em Anales de ArqueolEtnologia, Etnología, Mendonza, t. XXVII-XXVIII, p. 39-66. 19721973.

- Petroglifos no Estilo de Pisadas do Centro do Rio Grande do Sul. Pesquisas Antropologia, v. 34, p. 1-47, 1982. 


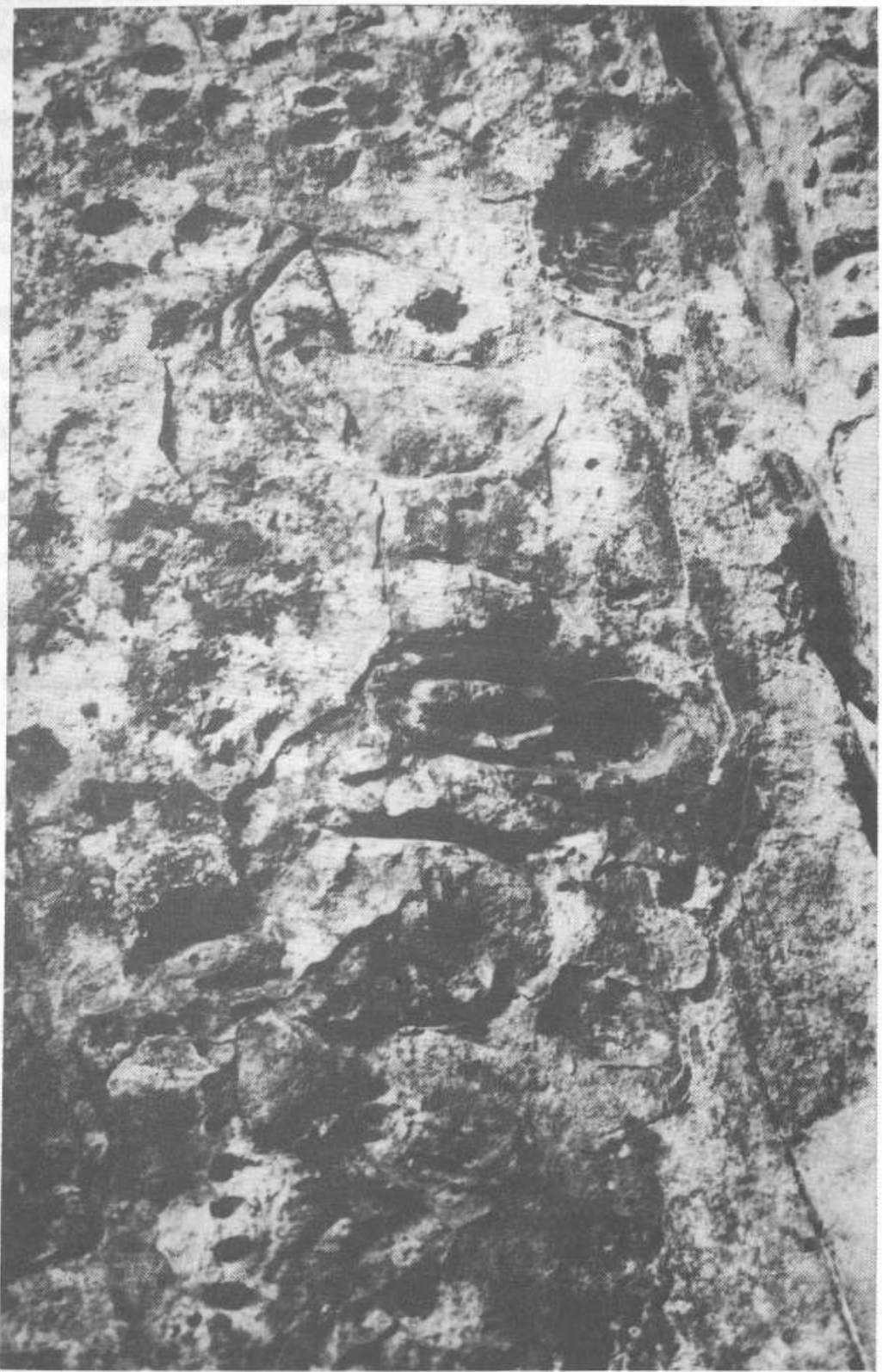




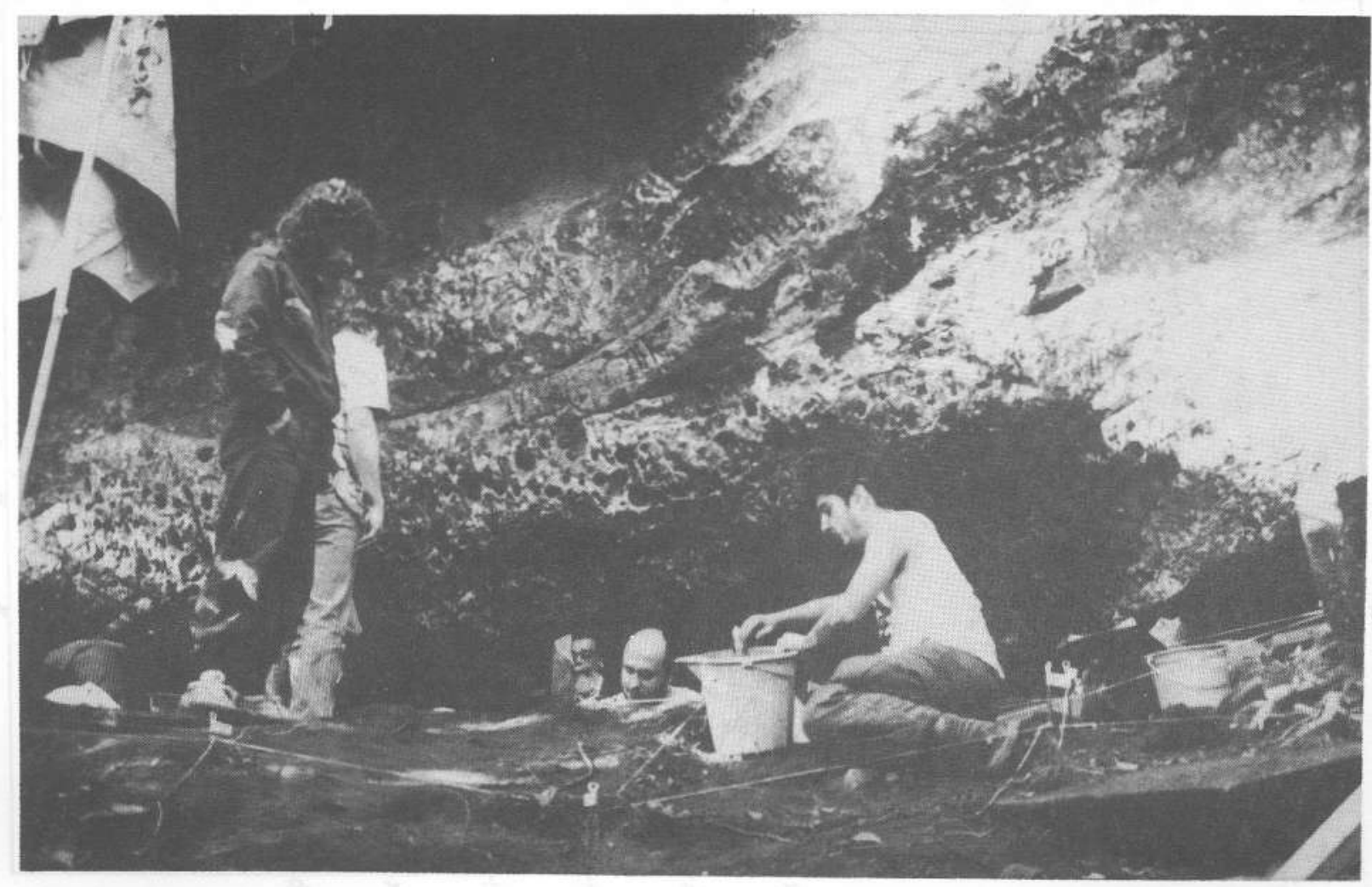

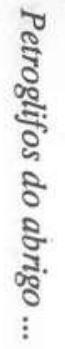




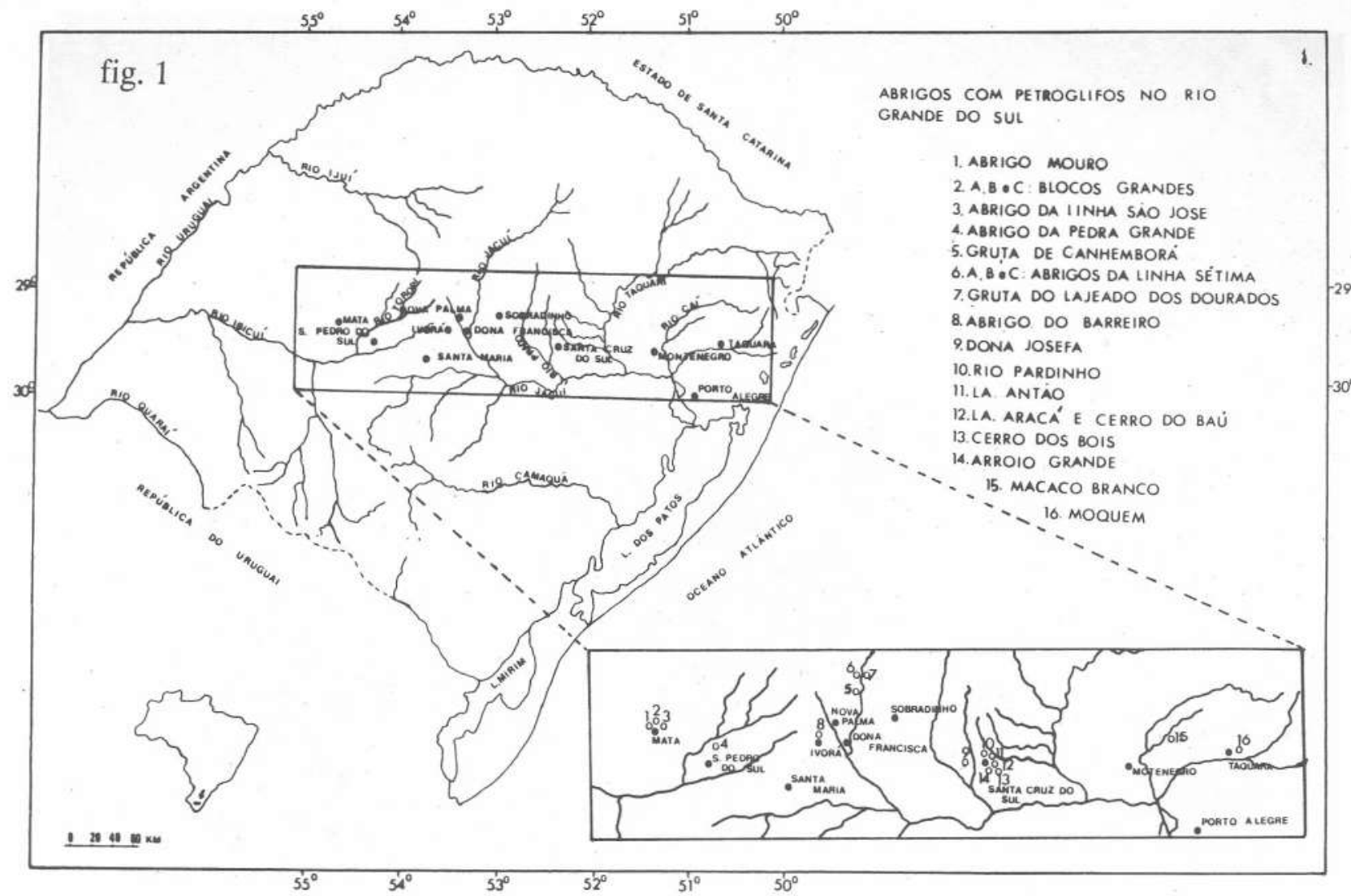


fig. 2

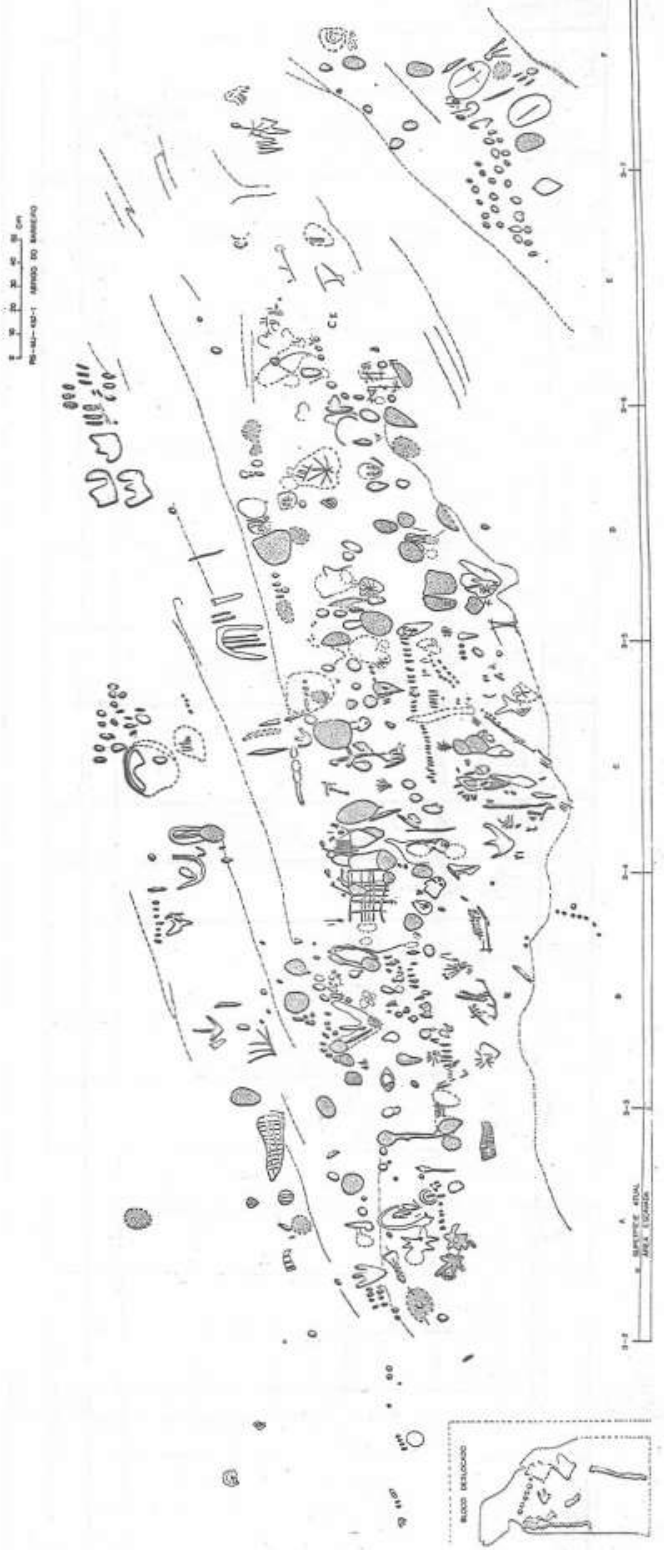


60

Estudos Ibero-Americanos, XX(1) - julho, 1994

fig. 3

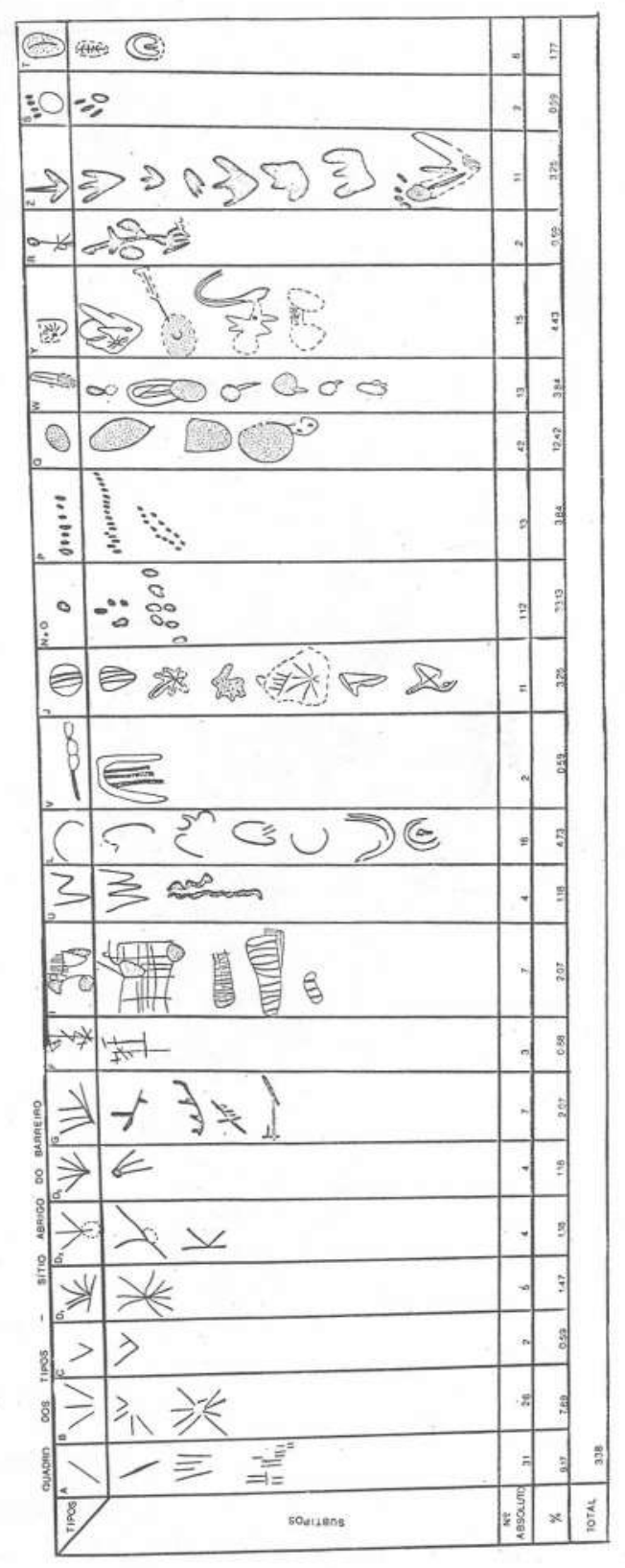


fig. 4
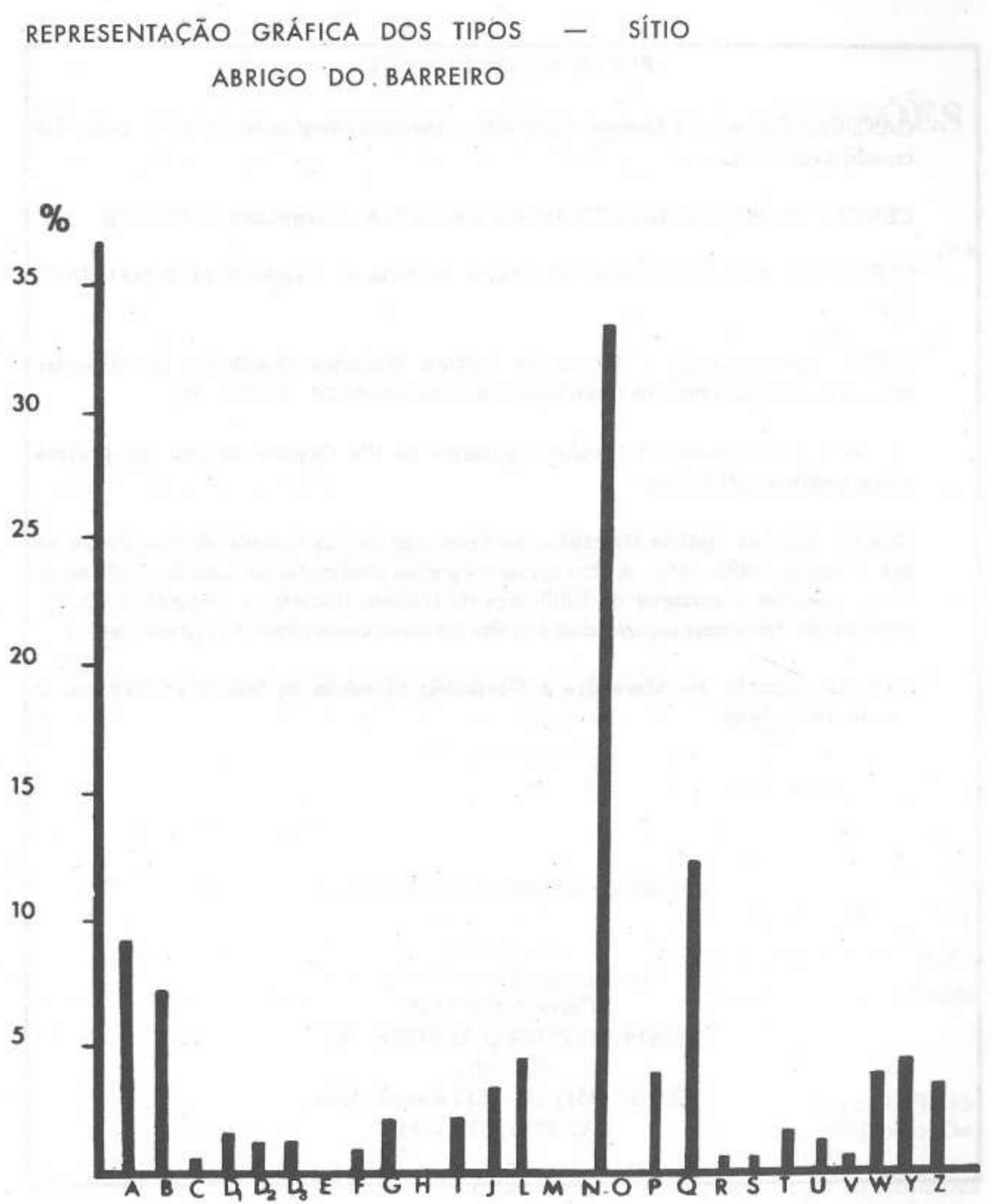